\title{
Percutaneous Endoscopic Gastrostomy Tube Gone Wrong: Endoscopic Closure to the Rescue
}

\author{
Jahnvi Dhar ${ }^{1}$ Naveen Kumar ${ }^{1} \quad$ Pankaj Gupta ${ }^{2} \quad$ Rakesh Kochhar $^{1} \quad$ Jayanta Samanta ${ }^{1, \odot}$ \\ ${ }^{1}$ Department of Gastroenterology, Postgraduate Institute of \\ Medical Education and Research, Chandigarh, India \\ ${ }^{2}$ Department of Radiodiagnosis and Imaging, Postgraduate Institute \\ of Medical Education and Research, Chandigarh, India

\begin{abstract}
Address for correspondence: Jayanta Samanta, DM, Department of Gastroenterology, Postgraduate Institute of Medical Education and Research, Sector 12, Chandigarh 160012, India (e-mail:dj_samanta@yahoo.co.in).
\end{abstract}

J Digest Endosc 2021;12:169-171.

\begin{abstract}
Keywords

- perforation

- over-the-scope clip

- pneumoperitoneum

- endotherapy

Percutaneous endoscopic gastrostomy (PEG) is one of the most commonly performed endoscopic procedures and a first-line treatment for the establishment of enteral access in those with intolerance or contraindication to oral feedings. A small amount of pneumoperitoneum in the immediate postprocedure period is well reported after PEG tube placement. However, pneumoperitoneum resulting from displaced gastric bumper within 24 hours postprocedure is uncommon and rarely reported in the literature. Timely diagnosis and early endoscopic management can help tackle such an unusual complication.
\end{abstract}

\section{Introduction}

A 68-year-old obese lady (body mass index [BMI]: $33.2 \mathrm{~kg} / \mathrm{m}^{2}$ ) was admitted with a diagnosis of severe acute necrotizing pancreatitis (ANP). At admission, she had both acute lung injury and acute kidney injury. She was managed conservatively with intravenous (IV) fluids, antibiotics, and percutaneous catheter drainage (PCD) of the ANC. She improved symptomatically but had poor oral intake. In view of expected prolonged nutritional support requirement and unwillingness to have nasojejunal tube placement, the patient was planned for a percutaneous endoscopic gastrostomy (PEG) placement on the eighth week of illness. PEG was placed using the pull-through technique and feeding was initiated the same day. The following day, postprocedure patient developed sudden onset abdominal pain and distension with feeding intolerance. Vitals were stable and abdominal examination revealed localized tenderness and guarding in the epigastrium but no rebound tenderness. A contrast enhanced CT showed pneumoperitoneum with a slipped out gastric bumper which was lying free in the peritoneum ( - Fig. 1; Video 1). After surgery consult and in view of absence of generalized peritonitis, endoscopic closure of the perforated gastric end ( - Fig. 2; Video 1 ) was planned with an over-the-scope clip (OTSC, OVESCO Endoscopy AG, Tübingen, Germany).

\section{Video 1}

CECT abdomen showing pneumoperitoneum with a slipped out gastric bumper end of PEG tube lying free in the peritoneum and increased fat pad thickness; upper GI scope mounted with the OVESCO clip and locating the perforated gastric end; suction applied to grab the perforation and sufficient tissue around it within the cap; OVESCO clip deployed, and perforated gastric end closed; post procedure, endoscopy revealed deployed OVESCO clip. CECT, contrast-enhanced computed tomography; GI, gastrointestinal; PEG, percutaneous endoscopic gastrostomy. Online content including video sequences viewable at: https:// www.thieme-connect.com/products/ejournals/html/ 10.1055/s-0041-1739563.
DOI https://doi.org/ $10.1055 / \mathrm{s}-0041-1739563$ ISSN 0976-5042 (c) 2021. Society of Gastrointestinal Endoscopy of India.

This is an open access article published by Thieme under the terms of the Creative Commons Attribution-NonDerivative-NonCommercial-License, permitting copying and reproduction so long as the original work is given appropriate credit. Contents may not be used for commercial purposes, or adapted, remixed, transformed or built upon. (https://creativecommons.org/licenses/by-nc-nd/4.0/). Thieme Medical and Scientific Publishers Pvt. Ltd. A-12, 2nd Floor, Sector 2, Noida-201301 UP, India 


\section{Procedure Details}

After confirming the location of the perforated gastric site endoscopically, an OTSC system (11 mm, type t) was mounted over a standard gastroscope (GIF-HQ190, Olympus Medical, Tokyo, Japan). The OTSC cap was bought in contact with the gastric wall (perforated end) and subsequently, suction was applied. Once sufficient amount of tissue around the perforation was sucked within the cap and the position ensured endoscopically, the clip was applied (-Fig. 3; Video 1). The procedure was performed using $\mathrm{CO}_{2}$ insufflation. Postprocedure, the patient improved symptomatically and was gradually started on oral feeds. Subsequently, her nutrition built up and was discharged in a hemodynamically stable condition.

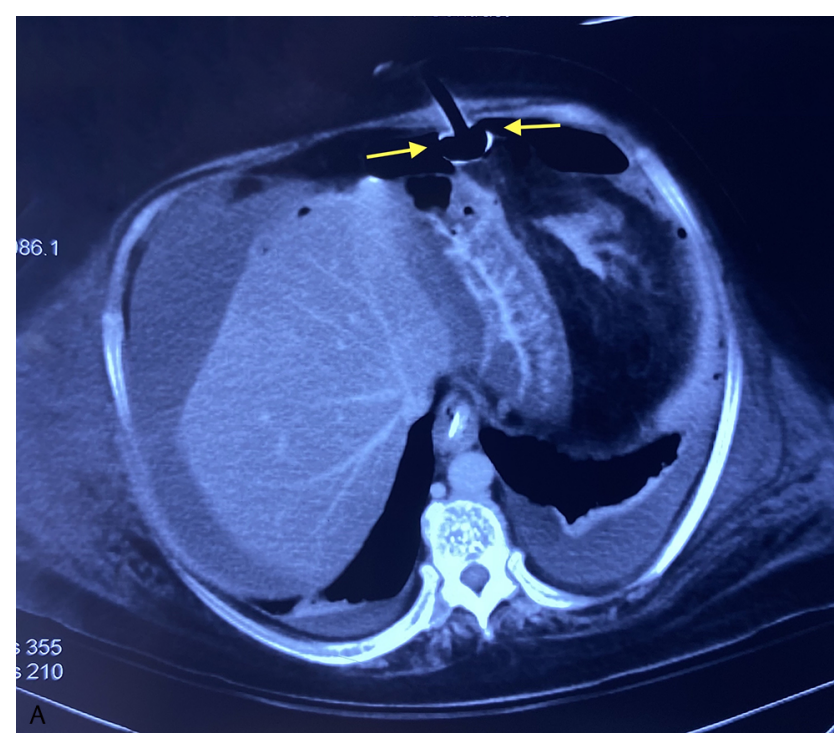

Fig. 1 Contrast-enhanced CT scan showing displaced gastric bumper of PEG tube (yellow arrow). CT, computed tomography; PEG, percutaneous endoscopic gastrostomy.

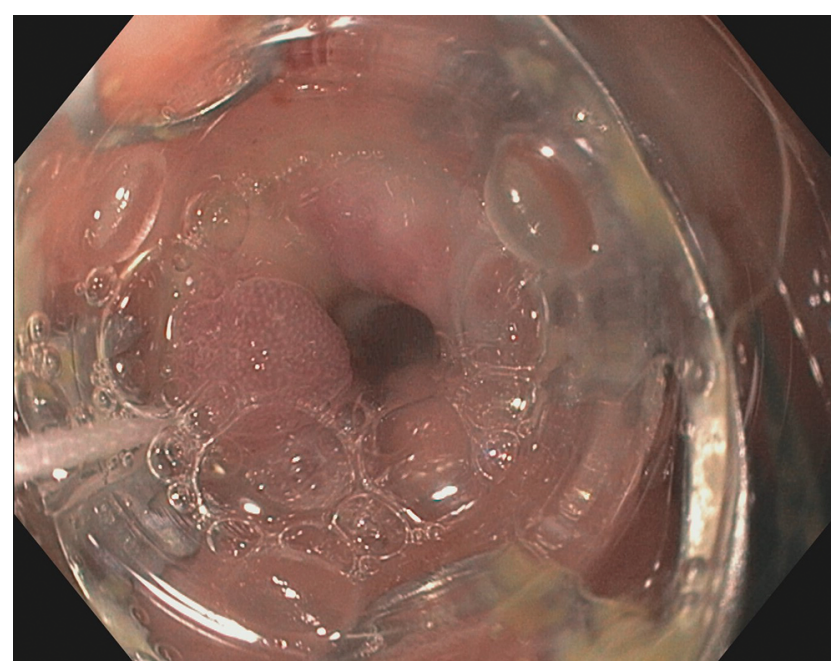

Fig. 2 Endoscopic image of the gastric perforation (previous PEC tube) site. PEG, percutaneous endoscopic gastrostomy.

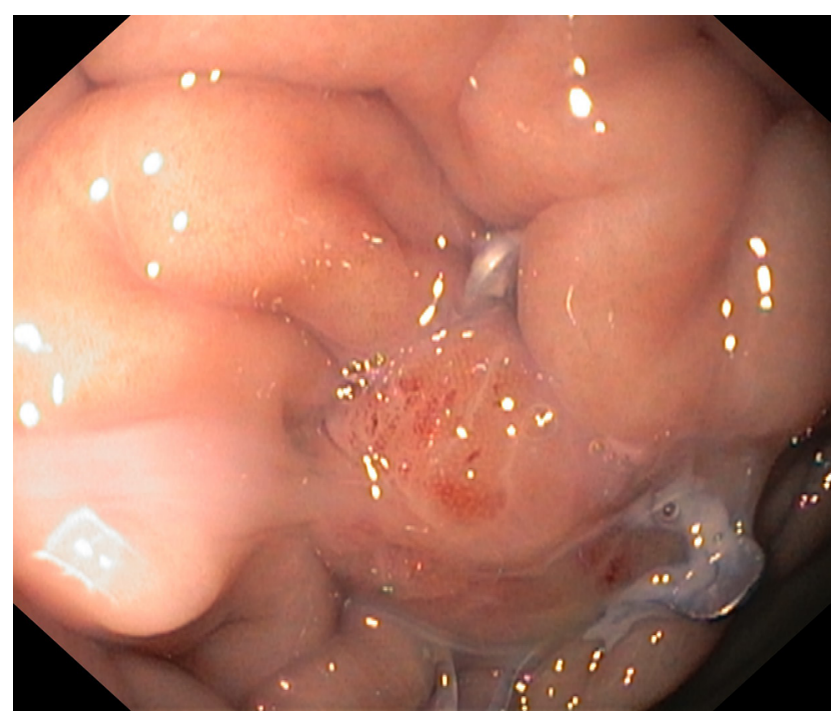

Fig. 3 Endoscopic image of the deployed OTSC closing the gastric perforation site. OTSC, over-the-scope clip.

\section{Learning Objectives}

Despite being a safe and feasible procedure, PEG placement is fraught with complications, ranging from 3 to $13 \%{ }^{1}$ Pneumoperitoneum is a benign, self-limiting complication encountered in 4.7 to $57 \%$ of the cases. ${ }^{2}$ It is commonly attributed to the air sufflation and needle puncture during the procedure. But post-PEG pneumoperitoneum, due to slipped gastric bumper, within 24 hours of the placement is uncommon. The usual management for a displaced PEG tube is to replace it which, technically, is easy when the tract has matured. This, however, was not there in the index case. The tract had not yet matured as PEG tube got displaced on the second day itself, and the large pneumoperitoneum had pushed the stomach wall away from the anterior abdominal wall. Hence, the gastric site had to be closed to prevent leakage of contents into the free peritoneum.

PEG tube placement for nutritional support in patients with acute necrotizing pancreatitis has been described earlier. ${ }^{3,4}$ Malposition of the gastrostomy tube, in such cases, has been managed conservatively or required peritoneal lavage or surgical intervention. However, none has described OTSC use, as in the index case, for closure of the gastric rent. OTSC have been used earlier for the closure of persistent/nonhealing gastrocutaneous fistula, after removal of PEG tube. ${ }^{5}$ However, OTSC use as a rescue therapy for such acute malposition of PEG tube is unique for the index case.

Some important caveats that must be kept in mind during PEG placement are as follows: (1) placement of PEG bumper tube inside the stomach should be confirmed endoscopically; (2) optimum traction should be given while fixing the PEG tube on the anterior abdominal wall to prevent displacement or leakage; (3) the procedure should be preferably performed under $\mathrm{CO}_{2}$ insufflation; (4) high index of suspicion should be kept for iatrogenic bowel injury, if the pneumoperitoneum persists beyond 72 hours; and (5) OTSC clips can 
be effectively used to endoscopically salvage complications of displaced PEG tube, as demonstrated in our index case. ${ }^{7}$

\section{Funding}

None.

\section{Conflict of Interest}

All the authors declare no potential conflicts of interest.

\section{References}

1 Larson DE, Burton DD, Schroeder KW, DiMagno EP. Percutaneous endoscopic gastrostomy. Indications, success, complications, and mortality in 314 consecutive patients. Gastroenterology 1987;93(1):48-52

2 Park WY, Lee TH, Lee JS, et al. . Reappraisal of pneumoperitoneum after percutaneous endoscopic gastrostomy. Intest Res 2015;13(4):313-317
3 Makola D, Krenitsky J, Parrish C, et al. . Efficacy of enteral nutrition for the treatment of pancreatitis using standard enteral formula. Am J Gastroenterol 2006;101(10):2347-2355

4 Roch AM, Carr RA, Watkins JL, et al. . Percutaneous gastrostomy in necrotizing pancreatitis: friend or foe? J Gastrointest Surg 2020;24(12):2800-2806

5 Singhal S, Changela K, Culliford A, Duddempudi S, Krishnaiah $\mathrm{M}$, Anand S. Endoscopic closure of persistent gastrocutaneous fistulae, after percutaneous endoscopic gastrostomy (PEG) tube placement, using the over-the-scope-clip system. Therap Adv Gastroenterol 2015;8(4):182-188

6 Wiesen AJ, Sideridis K, Fernandes A, et al. . True incidence and clinical significance of pneumoperitoneum after PEG placement: a prospective study. Gastrointest Endosc 2006;64(6): 886-889

7 Bartell N, Bittner K, Kaul V, Kothari TH, Kothari S. Clinical efficacy of the over-the-scope clip device: a systematic review. World J Gastroenterol 2020;26(24):3495-3516 